\title{
Impact of single vs. blended functional electrolyte additives on interphase formation and overall lithium ion battery performance
}

\author{
Natascha von Aspern ${ }^{1} \cdot$ Christian Wölke $^{1} \cdot$ Markus Börner $^{2} \cdot$ Martin Winter $^{1,2} \cdot$ Isidora Cekic-Laskovic $^{1}$ (D)
}

Received: 17 May 2020 / Revised: 7 July 2020 / Accepted: 21 July 2020 / Published online: 26 September 2020

(C) The Author(s) 2020

\begin{abstract}
Two functional high-voltage additives, namely 2-(2,2,3,3,3-pentafluoropropoxy)-1,3,2-dioxaphospholane (PFPOEPi) and 1methyl-3,5-bis(trifluoromethyl)-1 $H$-pyrazole (MBTFMP) were combined as functional additive mixture in organic carbonatebased electrolyte formulation for high-voltage lithium battery application. Their impact on the overall performance in NMC111 cathode-based cells was compared with the single-additive-containing electrolyte counterpart. The obtained results point to similar cycling performance of the additive mixture containing electrolyte formulation compared with the MBTFMPcontaining cells, whereas the single PFPOEPi-containing cells displayed the best cycling performance in NMC111||graphite cells. With regard to the cathode electrolyte interphase (CEI), characterized and analyzed by means of scanning electron microscopy (SEM) and X-ray photoelectron spectroscopy (XPS), both the MBTFMP and the PFPOEPi functional additives decompose on the NMC111 surface in single-additive-containing electrolyte formulations. However, the thickness of the CEI formed in the additive mixture-containing electrolyte formulation is determined by the MBTFMP additive, whereas the PFPOEPi additive impacts a change in the composition of the CEI. Furthermore, the MBTFMP additive decomposes prior to the PFPOEPi and, therefore, dominates the cycling performance of NMC111\|graphite cells containing functional additive mixture-based electrolyte. This systematic approach allows us to understand the synergistic impact of each functional additive in an electrolyte formulation containing an additive mixture and helps to identify the right additive combination for advanced electrolyte formulation as well as to elucidate whether the single-additive or the additive mixture approach is more effective for the development of advanced functional electrolytes for lithium-based cell chemistries.
\end{abstract}

\section{Introduction}

Lithium-based batteries (lithium ion batteries (LIB) and lithium metal batteries (LMB)) are still seen as the most promising electrochemical energy storage system candidates for automotive and portable applications [1-3].

Dedicated to Prof. Fritz Scholz on the occasion of his 65 th birthday

Electronic supplementary material The online version of this article (https://doi.org/10.1007/s10008-020-04781-1) contains supplementary material, which is available to authorized users.

Martin Winter

m.winter@fz-juelich.de

Isidora Cekic-Laskovic

i.cekic-laskovic@fz-juelich.de

1 Helmholtz Institute Münster, IEK-12, Forschungszentrum Jülich GmbH, Corrensstraße 46, 48149 Münster, Germany

2 MEET Battery Research Center, Westfälische Wilhelms-University Münster, Corrensstraße 46, 48149 Münster, Germany
However, due to the rapid increase and ever growing energy-related demands, novel, advanced electrode materials are highly demanded $[4,5]$, and the development of high-performing functional electrolytes is of equal crucial importance [6, 7]. Important aspects of this development, often considered as trivial and natural, comprise the study and understanding of the fundamental processes occurring at the different interfaces present in electrochemical systems, like for instance batteries by electrochemical or electroanalytical analyses [8-10]. Another aspect addresses utilizing insights on interface processes by substitution or addition of appropriate functional electrolyte components (conducting salt, solvent/co-solvent or functional/multifunctional additive) in order to tune the interface properties as needed [11-13]. In line with this strategy, the addition of at least two functional molecules with different structure to state-of-the-art (SOTA) electrolyte formulation represents an effective approach [6]. Different challenges related to the SOTA electrolyte comprising, for example, solid electrolyte interphase (SEI) 
formation at the anode|electrolyte interface, cathode electrolyte interphase (CEI) formation at the cathode|electrolyte surface, safety (overcharge protection and flammability issues) can be addressed [14-19], while the bulk physical properties of the SOTA electrolyte, which consists of $\mathrm{LiPF}_{6}$ as a conducting salt and a mixture of cyclic and linear organic carbonate-based solvents, remain mostly unaffected. The rapid increase in demand of high-energy density cells $[4,5]$ calls for increased cutoff cell voltage beyond $4.3 \mathrm{~V}[20,21]$, which can be enabled by addition of CEI functional additives [22]. Based on general literature research and our previous work, we have identified phospholane- [22] and pyrazole-based [23] functional additives as promising candidates for high voltage application. In both cases, a beneficial impact on the overall cell performance was shown when using $0.5 \mathrm{wt} . \%$ of the phospholanes or $5.0 \mathrm{wt} . \%$ of the pyrazoles as a single additive $[22,23]$. In case of the phospholane-based molecules, 2-(2,2,3,3,3pentafluoropropoxy)-1,3,2-dioxaphospholane (PFPOEPi) (Scheme 1) was identified as the most effective functional additive among the candidates for the development of advanced high-voltage electrolytes, as it forms an effective CEI via ring opening polymerization at the cathode/ electrolyte interface [22]. The pyrazole-based additive 1methyl-3,5-bis(trifluoromethyl)-1H-pyrazole (MBTFMP) (Scheme 1) forms an effective CEI on the cathode surface as well, due to the formation of a complex with the transition metals (Ni, Co, Mn) present in the cathode [23]. To combine the advantages of the phospholane- and pyrazole-based additives with respect to high voltage application, PFPOEPi and MBTFMP were combined in an electrolyte formulation for $\mathrm{LiNi}_{1 / 3} \mathrm{Mn}_{1 / 3} \mathrm{Co}_{1 / 3} \mathrm{O}_{2}$ (NMC111)||graphite cell chemistry. To identify the influence of each functional additive in the additive mixture containing electrolyte formulation, the obtained results were correlated to the single-additive electrolyte formulations. This approach allows us to determine the effect of the additive mixture vs. the single-additive approach on the overall cell performance.

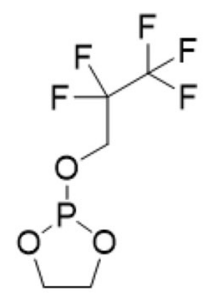

PFPOEPi

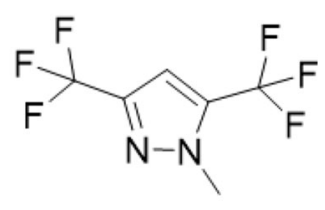

MBTFMP
Scheme 1 Chemical structures of considered high voltage functional electrolyte additives: 2-(2,2,3,3,3-pentafluoropropoxy)-1,3,2dioxaphospholane (PFPOEPi) and 1-methyl-3,5-bis(trifluoromethyl)$1 H$-pyrazole (MBTFMP)

\section{Experimental section}

\section{Synthesis of the phospholane and pyrazole functional additive}

2-(2,2,3,3,3-Pentafluoropropoxy)-1,3,2-dioxaphospholane (PFPOEPi) and 1-methyl-3,5-bis(trifluoro-methyl)- $1 H$ pyrazole (MBTFMP) molecules were synthesized according to our previous work $[22,23]$.

\section{Electrolyte formulation and cell assembly}

A 1-M LiPF 6 in ethylene carbonate (EC) and ethyl methyl carbonate (EMC) (1:1 by wt.) was used as a reference electrolyte (REF). The functional additive mixture containing electrolyte formulation contained $0.5 \mathrm{wt} \%$ of PFPOEPi and 5 wt.\% of MBTFMP in the REF. In the case of the singleadditive-containing electrolyte formulations, either $0.5 \mathrm{wt} . \%$ PFPOEPi or $5 \mathrm{wt} \%$ of MBTFMP were added to the REF. Graphite and NMC111 electrodes were provided by Customcells ${ }^{\circledR}$. One layer of Separion ${ }^{\circledR}$ was used as a separator. Electrodes and separators were dried at $120{ }^{\circ} \mathrm{C}$ under vacuum for $12 \mathrm{~h}$ prior to use. Swagelok® T-cells (for cyclic voltammetry), 2032-type coin cells (for electrochemical impedance spectroscopy), and house-made pouch cells (galvanostatic cycling) were assembled in either a glove box (MBraun, $\mathrm{H}_{2} \mathrm{O}$ and $\mathrm{O}_{2}<0.5 \mathrm{ppm}$ ) or in the dry room (dew point of at least $-60^{\circ} \mathrm{C}$ ).

\section{Electrochemical characterization}

For the cyclic voltammetry (CV) measurements, conducted at a VSP potentiostat (BioLogic) with a scan rate of $20 \mu \mathrm{V} \cdot \mathrm{s}^{-1}$, Swagelok ${ }^{\circledR}$ T-cells were assembled in a 3-electrode setup [24]. As working electrode, either graphite or NMC111 was used, whereas Li metal served as both counter and reference electrodes. The cells were cycled for three cycles in the potential range from 3.0 to $4.6 \mathrm{~V} \mathrm{vs.} \mathrm{Li}_{\mid} \mathrm{Li}^{+}$for $\mathrm{NMC} 111$ or from 0.025 to $1.5 \mathrm{~V}$ vs. $\mathrm{Li} \mid \mathrm{Li}^{+}$for graphite, starting from the open circuit potential (OCP) in both cases.

NMC111|graphite house-made electrode pouch cells $(5 \mathrm{~cm} \times 5 \mathrm{~cm})$ were assembled for the galvanostatic cycling experiments [24], conducted at a battery tester (MACCOR Series 4000). For the formation steps, cells were charged/discharged with a C-rate of $0.1 \mathrm{C}$ and $0.333 \mathrm{C}$ in the voltage range of $3.0-4.5 \mathrm{~V}$ for three cycles, respectively. At the end of the charge step, a 3-h constant voltage step was included. After the formation step, the cells were cycled with $1.0 \mathrm{C}$ for 100 charge/discharge cycles in the voltage range from 3.0 to $4.5 \mathrm{~V}$ at room temperature (RT). 


\section{EIS, SEM, EDX, and XPS analyses}

For postmortem studies, assembled pouch cells were galvanostatically cycled in the same voltage range (3.0 to $4.5 \mathrm{~V})$ until either formation or 100 charge/discharge cycles. The cells were charged to $50 \%$ of the lithiation degree and, thereafter, disassembled. Cathode and anode were separated from each other and used in the measurements.

For the electrochemical impedance spectroscopy (EIS) measurements, three different coin cell setups (graphite||graphite, NMC111\|graphite, NMC111\|NMC111) were considered, adopting the experimental approach of Petibon et al. [25]. The measurements were conducted on a VSP potentiostat (BioLogic) in the frequency range of $1 \mathrm{kHz}-$ $1 \mathrm{MHz}$.

Prior to the scanning electron microscopy (SEM) measurements, the considered electrodes were washed with dimethyl carbonate $(1 \mathrm{~mL})$ in the glove box and, thereafter, were analyzed with an Auriga ${ }^{\circledR}$ CrossBeam workstation from Zeiss with an accelerating voltage of $3 \mathrm{kV}$ and a working distance of $3 \mathrm{~mm}$, using the InLens detector.

In the case of X-ray photoelectron spectroscopy (XPS), considered electrodes were transferred into the instrument (Axis Ultra DLD, Kratos, U.K.) and kept under reduced pressure $\left(<10^{-8} \mathrm{mbar}\right)$ for $12 \mathrm{~h}$. Al $\mathrm{K} \alpha$ radiation with an energy of $1486.3 \mathrm{eV}$ was used, and an angle of either $0^{\circ}$ (cathode) or $45^{\circ}$ (anode) of emission was applied. A pass energy of $160 \mathrm{eV}$ at a $10-\mathrm{mA}$ filament current and a $12-\mathrm{kV}$ filament voltage source energy were used. The charging of the sample was compensated by the charge neutralizer. For the anodes, sputter depth profiling with a polyatomic ion gun (coronene as the ion source) was conducted. The sputter crater was 10 times larger than the selected measurement area, and the sputtering time was 60,120 , and $600 \mathrm{~s}$. For each sample, two to three data points with lateral resolution of $700 \mu \mathrm{m} \times 300 \mu \mathrm{m}$ were taken and arithmetically averaged. The obtained XPS spectra were fitted by using the CasaXPS software (Version 2.3.16 PR 1.6, Casa Software Ltd., U.K.) whereas the C $1 \mathrm{~s} \mathrm{C-H/CC} \mathrm{peak}$ was chosen as the internal standard for the binding energy (BE, $284.5 \mathrm{eV}$ ) calibration. The relative composition and thickness of the surface layer were calculated based on the work of Niehoff et al. [26, 27].

\section{Results and discussion}

For the functional additive mixture-containing electrolyte formulation with advanced performance, appropriate selection of single functional additives and their amount in the additive mixture is a priority [6]. In line with this, a concentration screening for the optimum concentration of each functional additive (phospholane and pyrazole) in the additive mixture containing electrolyte formulation was conducted (Fig. SI 1).
The obtained results reveal that the combination of $0.5 \%$ PFPOEPi and 5\% MBTFMP stands for the optimized additive mixture and was therefore used for further characterization and comparison to single-additive-containing analogues. To elucidate the impact of the functional additive mixture containing electrolyte formulation, galvanostatic cycling experiments were conducted and correlated to the corresponding single functional additive-containing electrolyte formulations. The obtained results are depicted in Fig. 1.

After the first charge/discharge cycle, the following order in respect to the Coulombic efficiency values was observed: REF + 0.5\% PFPOEPi + 5\% MBTFMP $(76.3 \%)<$ REF + MBTFMP $(77.3 \%)<\operatorname{REF}(82.2) \approx \mathrm{REF}+0.5 \%$ PFPOEPi. Here, the cell with the functional additive mixturecontaining electrolyte formulation behaves similarly to the single MBTFMP-containing cell and no positive influence of the PFPOEPi functional additive is noticeable. Moreover, the cycling stability of the functional additive mixturecontaining cells is similar to the single MBTFMP-containing

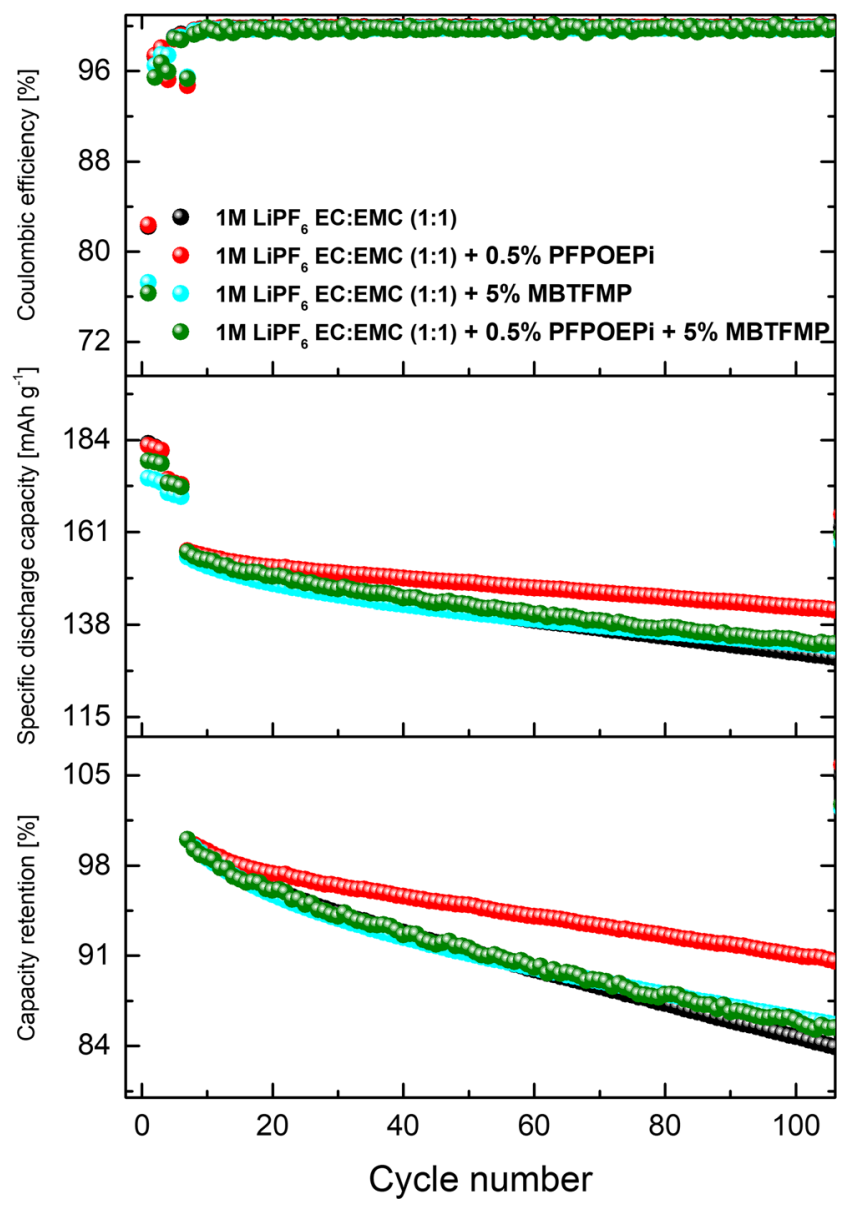

Fig. 1 Coulombic efficiencies (top), specific discharge capacities (middle), and the capacity retentions (bottom) vs. cycle number of the four electrolyte formulations ( $1 \mathrm{M} \mathrm{LiPF}_{6} \mathrm{EC}: \mathrm{EMC}$ (1:1 by wt.) (REF), $\mathrm{REF}+0.5 \% \mathrm{PFPOEPi}, \mathrm{REF}+5 \% \mathrm{MBTFMP}$, and $\mathrm{REF}+0.5 \%$ PFPOEPi $+5 \%$ MBTFMP) in NMC111\|graphite cells at $20{ }^{\circ} \mathrm{C}$ with an upper cutoff voltage of $4.5 \mathrm{~V}$ 
cell, and only a slight improvement to the REF-containing cell is observed. The cycling stability of the single PFPOEPicontaining cell is much higher; however, the influence of the PFPOEPi functional additive in the additive mixturecontaining electrolyte formulation seems to be negligible. To exclude the electrochemical impact of the PFPOEPi functional additive in the additive mixture-containing electrolyte formulation on the cycling performance, $\mathrm{CV}$ measurements of graphite||Li and NMC111||Li cells containing considered electrolyte formulations were conducted, as depicted in Fig. 2.

Figure 2a illustrates the cyclic voltammograms of the graphite||Li cells. The REF and the PFPOEPi-containing electrolytes display good compatibility with the graphite anode, whereas for the MBTFMP-containing cell, a decomposition with the peak maximum at $0.8 \mathrm{~V} \mathrm{vs.} \mathrm{Li}^{\mid} \mathrm{Li}^{+}$is observed. These findings are in good agreement with the theoretically calculated reduction potentials, as they point out that MBTFMP decomposes prior to the other electrolyte components, whereas PFPOEPi is more reductively stable than EC and EMC [22, 23]. The CV results related to the functional additive mixturecontaining electrolyte formulation, however, display no additional peak at $0.8 \mathrm{~V}$ vs. $\mathrm{Li}^{-} \mathrm{Li}^{+}$. This implies that PFPOEPi must somehow interfere with the decomposition reaction of MBTFMP, which leads to the suppression of the decomposition of the MBTFMP functional additive. On the oxidation side (Fig. 2b), the PFPOEPi-containing cell displays no additional decomposition peak compared with the REF-containing cell, whereas for the MBTFMP-containing and the additive mixture-containing analogues, an additional decomposition peak can be observed at the potential of $4.5 \mathrm{~V}$ vs. $\mathrm{Li}^{-\mathrm{Li}^{+}}$. This means that the oxidation potential of the additive mixture-containing electrolyte formulation is mainly driven by the MBTFMP molecule. When comparing these findings with the calculated oxidation potentials, a clear disagreement is observed. As the theoretically determined values indicate that PFPOEPi (oxidation potential of $5.09 \mathrm{~V}$ vs. $\mathrm{Li}^{2} \mathrm{Li}^{+}$[22]) decomposes prior to MBTFMP (oxidation potential of $5.77 \mathrm{~V}$ vs. $\mathrm{Li}^{2} \mathrm{Li}^{+}[23]$ ), the experimental results of the single-additive-containing electrolyte cells, however, reveal that the MBTFMP-containing electrolyte decomposes prior to the
PFPOEPi-containing analogue. The theoretical approach of considering the oxidation potential reveals to be too simplistic as for the calculation of a single isolated molecule is used. Moreover, the calculated values suggest that PFPOEPi should have the main impact in CEI formation of the additive mixture-containing electrolyte formulation.

The obtained experimental results indicate that MBTFMP is the driving force of the decomposition reaction on the cathode, whereas PFPOEPi suppresses the decomposition of MBTFMP on the anode surface.

The electrochemical impact of PFPOEPi in the additive mixture-containing electrolyte formulation was confirmed by EIS measurements as illustrated in Fig. 3.

The pouch cells with considered electrolyte formulations were cycled for either formation state or for 100 charge/ discharge cycles and thereafter, charged to $50 \%$ of the lithiation degree. To determine the influence of each electrode, symmetric graphite||graphite and NMC111||NMC111 cells as well as NMC111||graphite cells were assembled (see ref. [24]). The obtained results were interpreted according to Zhao et al. [28]. Here, the $x$-axis interception in the Nyquist plot represents the electrolyte resistance $\left(\mathrm{R}_{\mathrm{el}}\right)$, the first semicircle the interface/interphase resistance $\left(\mathrm{R}_{\mathrm{SEI}}, \mathrm{R}_{\mathrm{CEI}}, \mathrm{R}_{\mathrm{Int}}\right)$ at the considered electrodes, and the second semicircle the charge transfer resistance $\left(\mathrm{R}_{\mathrm{ct}}\right)$. As the obtained cycling results reveal that the impact of the PFPOEPi additive in the additive mixture-containing electrolyte formulation is negligible; however, the obtained EIS results (Fig. 3) display an influence of the PFPOEPi additive in the additive mixture-containing electrolyte formulation. First of all, the impedance growth during prolonged cycling is driven by the cathode side for all considered electrolyte formulations as the overall impedance in the NMC111||NMC111 cells increases significantly compared with the graphite $\|$ graphite cells. When looking more closely into the NMC111|NMC111 cell results, it can be seen that the impedance of $\mathrm{R}_{\mathrm{CEI}}$ is the lowest in the case of the additive mixture-containing electrolyte formulation, while the $\mathrm{R}_{\mathrm{CEI}}$ for the REF- and the MBTFMP-containing cell is similar. The PFPOEPi-containing cell displays the highest $\mathrm{R}_{\mathrm{CEI}}$. In the case of the charge transfer resistance, after
Fig. 2 First cycle cyclic voltammograms of the (a) graphite $\| \mathrm{Li}$ and (b) $\mathrm{NMC1} 11 \| \mathrm{Li}$ cell-containing considered electrolyte formulations (1 M $\mathrm{LiPF}_{6}$ EC:EMC (1:1 by wt.) (REF), REF + 0.5\% PFPOEPi, $\mathrm{REF}+5 \%$ MBTFMP, and $\mathrm{REF}+0.5 \%$ PFPOEPi $+5 \%$ MBTFMP)
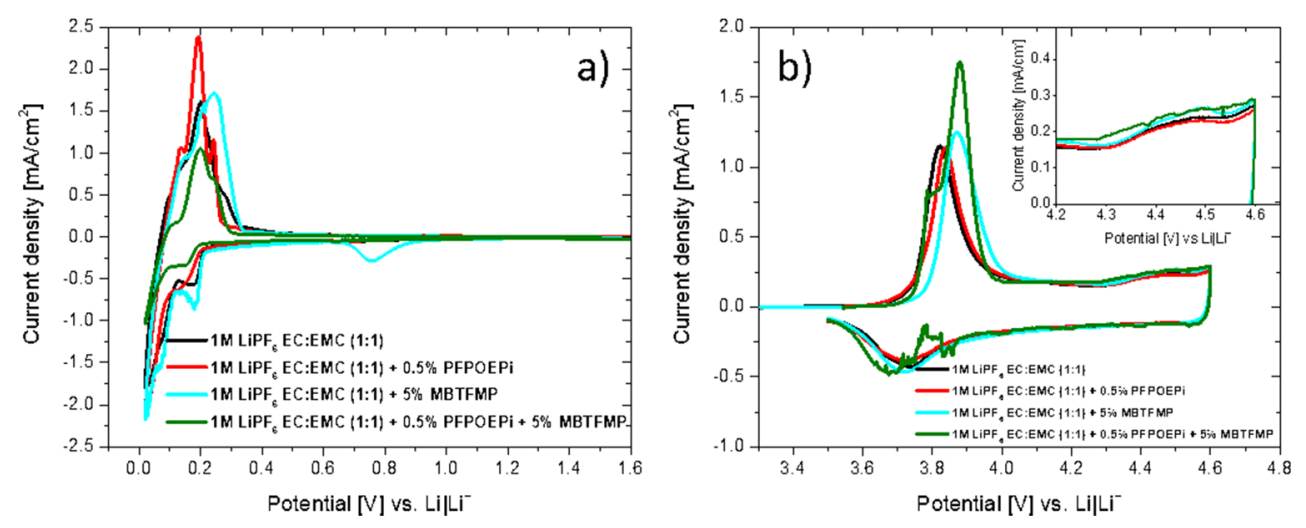

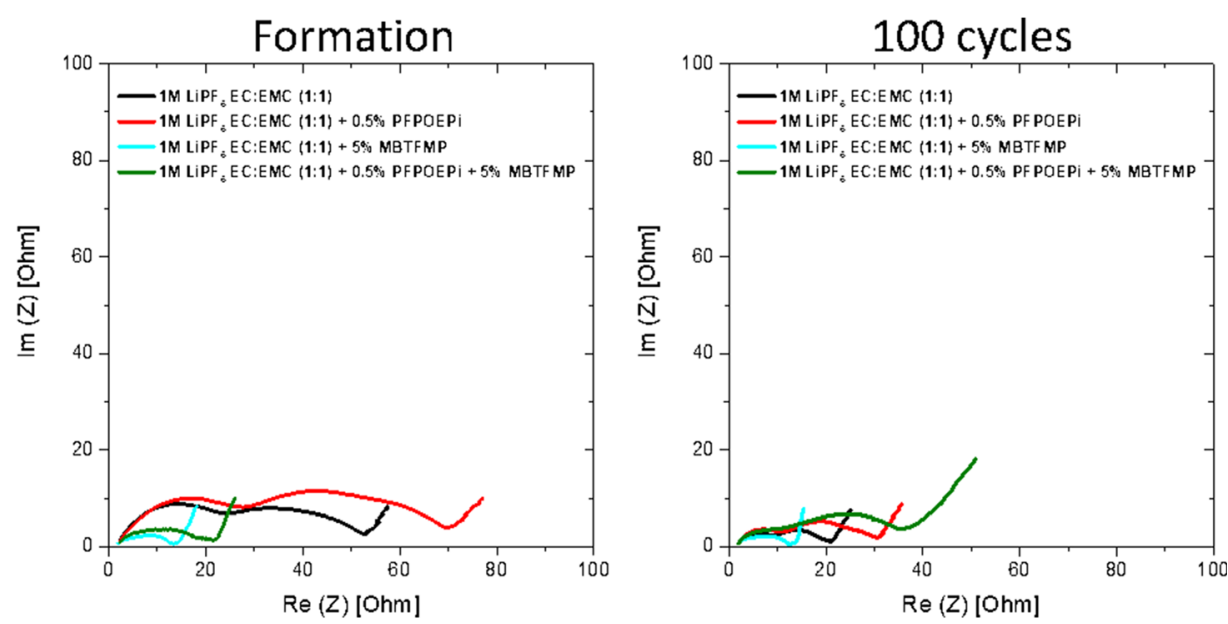

Graphite ||Graphite cells
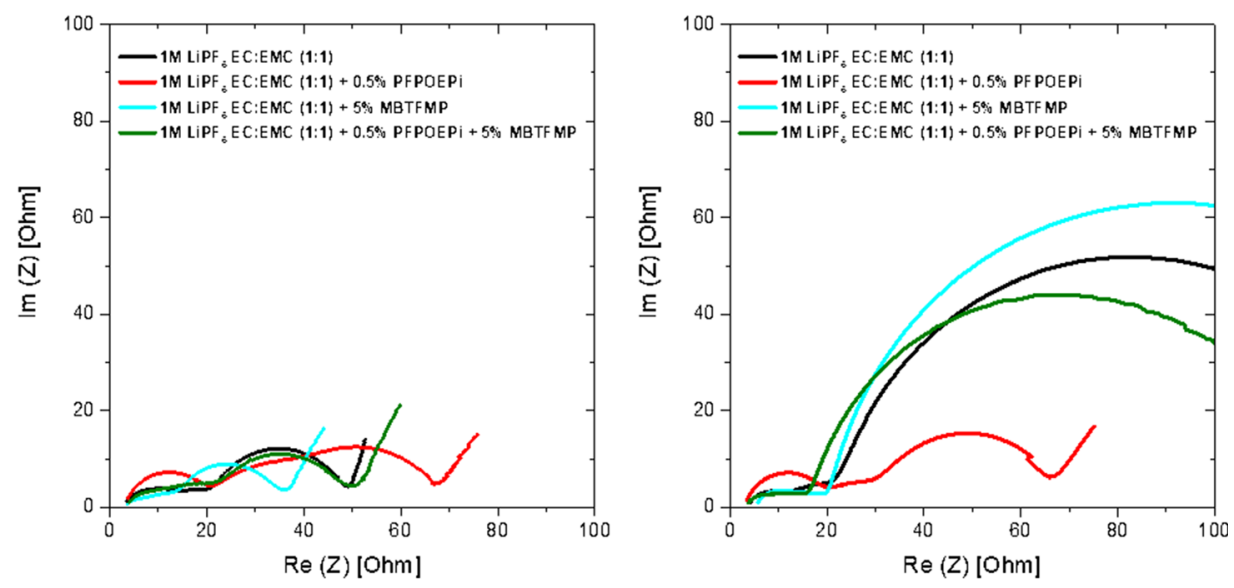

NMC111||Graphite cells
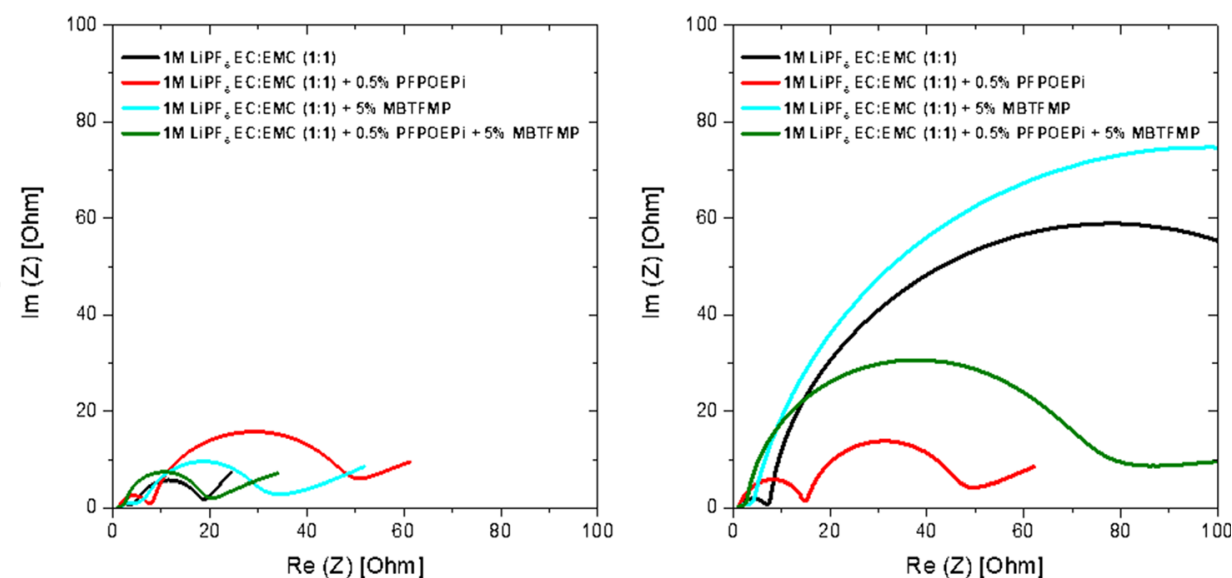

Fig. 3 EIS spectra of the four electrolyte formulations (1 $\mathrm{M} \mathrm{LiPF}_{6}$ EC:EMC (1:1 by wt.) (REF), REF + 0.5\% PFPOEPi, REF $+5 \%$ MBTFMP, and REF + $0.5 \%$ PFPOEPi $+5 \%$ MBTFMP) in

graphite||graphite (top), NMC111\|graphite (middle), and NMC111||NMC111 (bottom) cells after formation (left column) as well as after 100 charge/discharge cycles (right column) at $20^{\circ} \mathrm{C}$

formation, the REF-containing cells have the lowest resistance followed by the additive mixture counterpart, the MBTFMPand the PFPOEPi-containing electrolyte formulation-based cells. Herein, no influence of either functional additive can be distinguished for the additive mixture-containing electrolyte formulation. However, after 100 charge/discharge cycles, the influence of each additive in the additive mixturecontaining electrolyte formulation becomes observable. $\mathrm{R}_{\mathrm{CEI}}$ does not increase during prolonged cycling for the additive mixture-containing electrolyte, which can be clearly assigned to the MBTFMP-containing cells, as it also displays a constant $\mathrm{R}_{\mathrm{CEI}}$ during prolonged cycling, whereas $\mathrm{R}_{\mathrm{CEI}}$ for the PFPOEPi-containing cells increases during prolonged cycling. In the case of $\mathrm{R}_{\mathrm{ct}}$, the main influence for the increasing second semicircle for the additive mixture-containing electrolyte formulation originates from both functional additives. For 
PFPOEPi-containing cells, $R_{c t}$ does not increase, whereas a drastic increase for the MBTFMP-containing cells is noticeable during prolonged cycling. The synergistic effect of the phospholane and pyrazole functional additives in the additive mixture-containing electrolyte formulation leads to an $\mathrm{R}_{\mathrm{ct}}$ which lies between the values of the single PFPOEPi- and MBTFMP-containing cells. With this, we can conclude that the PFPOEPi additive has a positive influence on the resistance of the additive mixture-containing electrolyte formulation; however, as the cycling results reveal, an impact on the decreased $R_{c t}$ is not observable. Moreover, the influence of the MBTFMP additive on the constant $\mathrm{R}_{\mathrm{CEI}}$ seems to be more important. In the case of the graphite||graphite cells, the impact of the PFPOEPi additive in the additive mixture-containing electrolyte formulation is more pronounced. After formation, the following order of the overall impedance can be observed: $\mathrm{REF}+5 \%$ MBTFMP $<\mathrm{REF}+0.5 \% \mathrm{PFPOEP} i+5 \%$ MBTFMP $\approx$ REF $<$ REF $+0.5 \%$ PFPOEPi. After 100 charge/discharge cycles, the overall impedance for the MBTFMP-containing cell does not change, whereas for the PFPOEPi, it decreases compared with the after-formation state. In the case of the additive mixture-containing electrolyte formulation, the overall impedance increases and is the same as for the PFPOEPi-containing cells after 100 charge/ discharge cycles. However, this impact of PFPOEPi additive in the additive mixture-containing electrolyte formulation displays only a minor impact, as the significant increase in the NMC111 |graphite cells is driven by the cathode surface and is mainly responsible for the cycling performances displayed in Fig. 1.

To elucidate the impact of MBTFMP and PFPOEPi on the CEI formation, postmortem analysis was performed by means of SEM and XPS analyses of the NMC111 electrodes. The obtained SEM results are depicted in Fig. 4.

The obtained SEM images of the NMC111 electrodes with REF after formation show presence of decomposition products on the electrode surface, whereas after 100 charge/ discharge cycles, the electrode particles are completely covered by a layer of decomposition products. In the case of the phospholane-containing cells after formation, additional spherically shaped decomposition products can be observed. For the PFPOEPi-containing cell, the electrode surface after 100 charge/discharge cycles appears to be unaffected compared with the cathode surface after formation. For the MBTFMP-containing cells, after formation, small decomposition spots are observable, and their amount does not increase during prolonged cycling. In the case of the additive mixturecontaining electrolyte formulation-based cells, the surface of the NMC111 electrode is covered by decomposition products after formation. After 100 charge/discharge cycles, decomposition products are still observable for the additive mixturecontaining electrolyte formulation and remain unaffected during prolonged cycling. As the same behavior could be observed for the single-additive-containing cells, an influence of individual additives on CEI formation could not be distinguished.

To get a deeper understanding of the impact of each functional additive on CEI formation and composition, XPS analysis was performed. The corresponding XPS results of the composition and the thickness of the CEI of the NMC111 electrodes determined by the mathematical approach developed by Niehoff et al. [26, 27] are depicted in Fig. 5 .

After formation, a significant difference between the formed CEI on the NMC111 surface, driven by the different electrolyte formulations, can be observed (REF $+0.5 \%$ $\mathrm{PFPOEP} i<\mathrm{REF}<\mathrm{REF}+5 \% \mathrm{MBTFMP} \approx \mathrm{REF}+0.5 \%$ PFPOEPi $+5 \%$ MBTFMP). During 100 charge/discharge cycles, the CEI thickness of the MBTFMP-containing cell remains unaffected, whereas the thickness of CEI of the PFPOEPi-containing cells significantly increases. In the case of the additive mixture-containing electrolyte formulation, only a slight increase in the CEI thickness from formation to 100 charge/discharge cycles is observed. This results in CEI thicknesses of the following order: REF $+0.5 \%$ PFPOEPi $<$ $\mathrm{REF}<\mathrm{REF}+5 \% \mathrm{MBTFMP}<\mathrm{REF}+0.5 \%$ PFPOEPi $+5 \%$ MBTFMP, indicating that the thickness of the CEI in the additive mixture-containing electrolyte formulation is mainly determined by the MBTFMP additive. When looking into the composition of the CEI, a significant influence of PFPOEPi additive in the additive mixture-containing cells can be observed. Firstly, a smaller content of LiF for the additive mixture-containing electrolyte formulation after formation as well as after 100 charge/discharge cycles compared with the MBTFMP-containing cells is noticeable. The decreased $\mathrm{LiF}$ content is probably due to the presence of the PFPOEPi additive, as the cells containing only PFPOEPi display a very low content of LiF in the CEI. Secondly, in the case of the MBTFMP and the additive mixture electrolyte-containing cells a nitrogen peak can be observed. In both cases, this means that the MBTFMP additive decomposes on the NMC111 electrode surface. Due to the fact that the nitrogen concentration does not change during prolonged cycling in both cases it can be assumed that the decomposition of MBTFMP functional additive occurs during formation. In addition, the thickness is similar in both cases and indicates that the same amount of MBTFMP additive decomposes on the NMC111 surface. The CEI of the MBTFMP-containing cells displays a $\mathrm{CF}_{3}$ thickness of $0.04 \mathrm{~nm}$ after 100 charge/ discharge cycles, whereas the additive mixture-containing

Fig. 4 SEM images of the NMC111 electrodes obtained from cells with the four considered electrolyte formulations ( $1 \mathrm{M} \mathrm{LiPF}_{6} \mathrm{EC}$ :EMC (1:1 by wt.) (REF), REF + 0.5\% PFPOEPi, REF + 5\% MBTFMP, and REF + $0.5 \%$ PFPOEPi $+5 \%$ MBTFMP) after formation, and 100 charge/ discharge cycles as well as the pristine electrode 

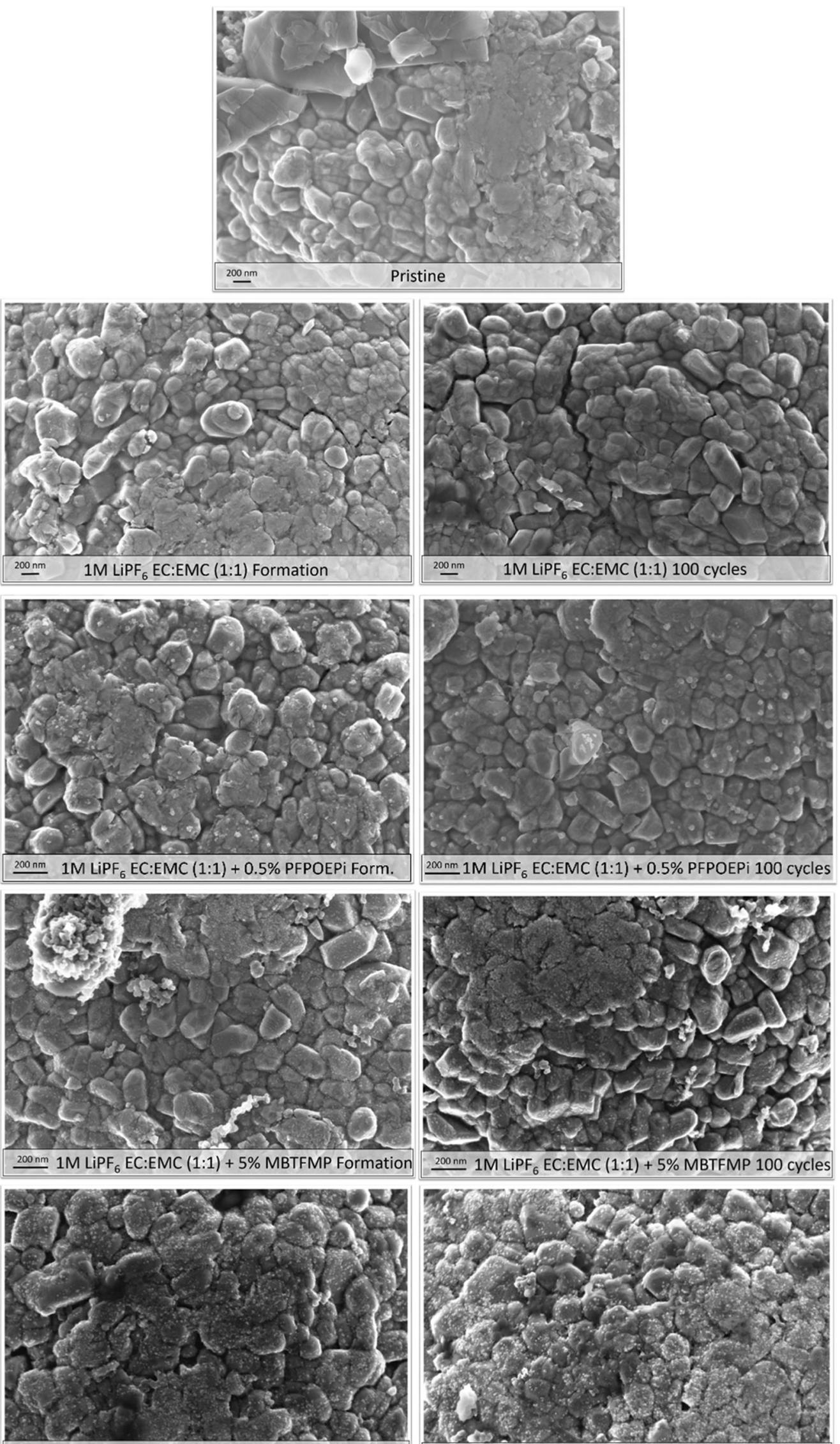

$200 \mathrm{~nm} 1 \mathrm{M} \mathrm{LiPF}_{6}$ EC:EMC $(1: 1)+5.0 \%$ MBTFMP + 0.5\% PFPOEPi Formation

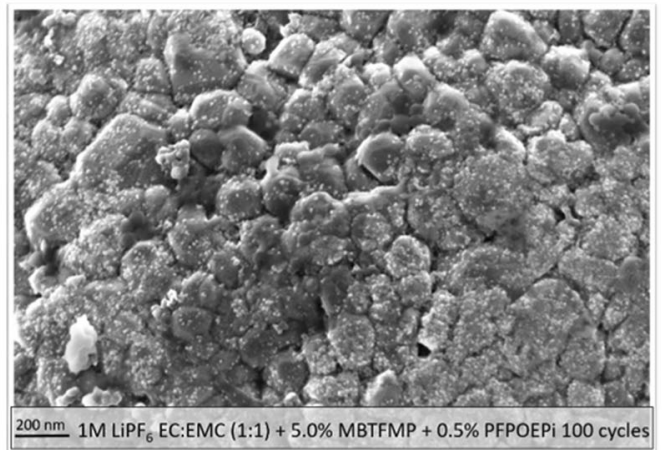




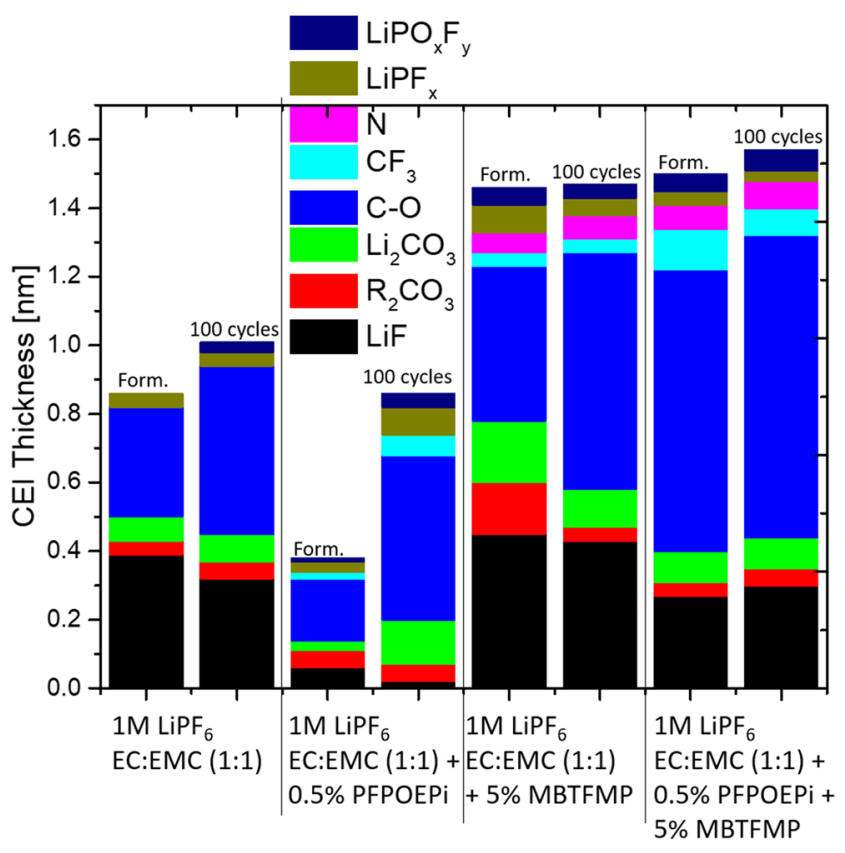

Fig. 5 Determined thicknesses and compositions of the CEIs obtained in the four different electrolyte formulations ( $1 \mathrm{M} \mathrm{LiPF}_{6} \mathrm{EC}$ :EMC (1:1 by wt.) (REF), REF + 0.5\% PFPOEPi, REF + 5\% MBTFMP, and REF + $0.5 \%$ PFPOEPi $+5 \%$ MBTFMP) after formation and 100 charge/ discharge cycles

electrolyte formulation has a thickness of $0.08 \mathrm{~nm}$ after 100 charge/discharge cycles. In addition, an increase of the $\mathrm{CF}_{3}$ content in the CEI layer from formation to 100 charge/ discharge cycles is observable while the nitrogen content is constant. This means that the increase in the $\mathrm{CF}_{3}$ content does not originate from the MBTFMP molecule. Due to the fact that the PFPOEPi molecule possesses a $\mathrm{CF}_{3}$ group in the structure, the increase of the $\mathrm{CF}_{3}$ content in the CEI layer in the additive mixture-containing electrolyte formulation can be clearly assigned to the decomposition of the PFPOEPi additive on the NMC111 surface. Furthermore, an increase in the $\mathrm{C}-\mathrm{O}$ content in the CEI layer from $0.69 \mathrm{~nm}$ for the MBTFMP-containing cell to $0.88 \mathrm{~nm}$ for the additive mixture-containing electrolyte formulation can be observed after 100 charge/discharge cycles. As known from our previous work [23], phospholane molecules tend to decompose on the NMC111 surface via ring opening polymerization reaction, the increasing $\mathrm{C}-\mathrm{O}$ content cannot be assigned only to the PEO decomposition product but also indicates the phospholane decomposition. Together with the increased $\mathrm{CF}_{3}$ content, it can be concluded that the PFPOEPi additive decomposes in the additive mixture-containing electrolyte formulation on the NMC111 surface as well. However, obtained cycling results (Fig. 1) as well as the EIS results (Fig. 3) performed in the NMC111|NMC111 cells suggest no impact of the PFPOEPi on the CEI formation. The obtained XPS results reveal that both functional additives decompose on the NMC111 electrode surface. Due to the fact that the cycling performance of the cell with additive mixture-containing electrolyte formulation is the same as for the MBTFMPcontaining cell, it can be concluded that the impact of the PFPOEPi additive, which changes the composition of the $\mathrm{CEI}$, is negligible. Furthermore, the CEI thickness, induced by the MBTFMP additive, is the main driving force for the cycling performance of the additive mixture containing cells. In line with this conclusion, it can be deducted that the MBTFMP additive has the main impact on the CEI formation and dynamics. The positive effects of the decomposition of the PFPOEPi additive on the NMC111 electrode surface are suppressed, which is the reason why the addition of the PFPOEPi additive to the MBTFMP additive-containing electrolyte formulation has no positive impact on cycling performance.

As the CV results of the graphite||Li cells (Fig. 2a) and the EIS results (Fig. 3) of the graphite||graphite cells reveal, the PFPOEPi additive displays a more significant impact on the anode side than on the cathode side in the additive mixturecontaining electrolyte formulation. For this reason, the SEI on the graphite anode was analyzed by means of SEM, and the obtained results are depicted in Fig. 6. The SEM images of the graphite electrodes reveal decomposition products after formation cycles in the case of REF, whereas after 100 charge/ discharge cycles, the surface is completely covered with decomposition products. When comparing the PFPOEPicontaining cells with the REF-containing cells after formation, more decomposition products for PFPOEPi-containing cells are observed, whereas after 100 charge/discharge cycles, the surface of the graphite electrode cycled with the REF displays more decomposition products compared with the PFPOEPicontaining cells. In the case of the MBTFMP-containing cells, electrolyte decomposition products are observed; however, their amount does not increase during prolonged cycling and, therefore, less decomposition products are present on the graphite surface compared with the cells containing REF after 100 charge/discharge cycles. In addition, the amount of the decomposition products is similar to the PFPOEPicontaining cells. For the additive mixture electrolyte formulation-containing cells, decomposition products are observable in a low amount after formation. Their amount however, increases during prolonged cycling. The decomposition amount is less than with the REF-containing cells, but more than in the PFPOEPi- and MBTFMP-containing cells.

To evaluate the impact of each additive in the additive mixture containing electrolyte formulation on the thickness

Fig. 6 SEM images of the graphite electrodes obtained from cells with the four considered electrolyte formulations ( $1 \mathrm{M} \mathrm{LiPF}_{6} \mathrm{EC}: \mathrm{EMC}$ (1:1 by wt.) (REF), REF + 0.5\% PFPOEPi, REF + 5.0\% MBTFMP, and REF + $0.5 \%$ PFPOEPi $+5.0 \%$ MBTFMP) after formation and 100 charge/ discharge cycles as well as the pristine electrode 

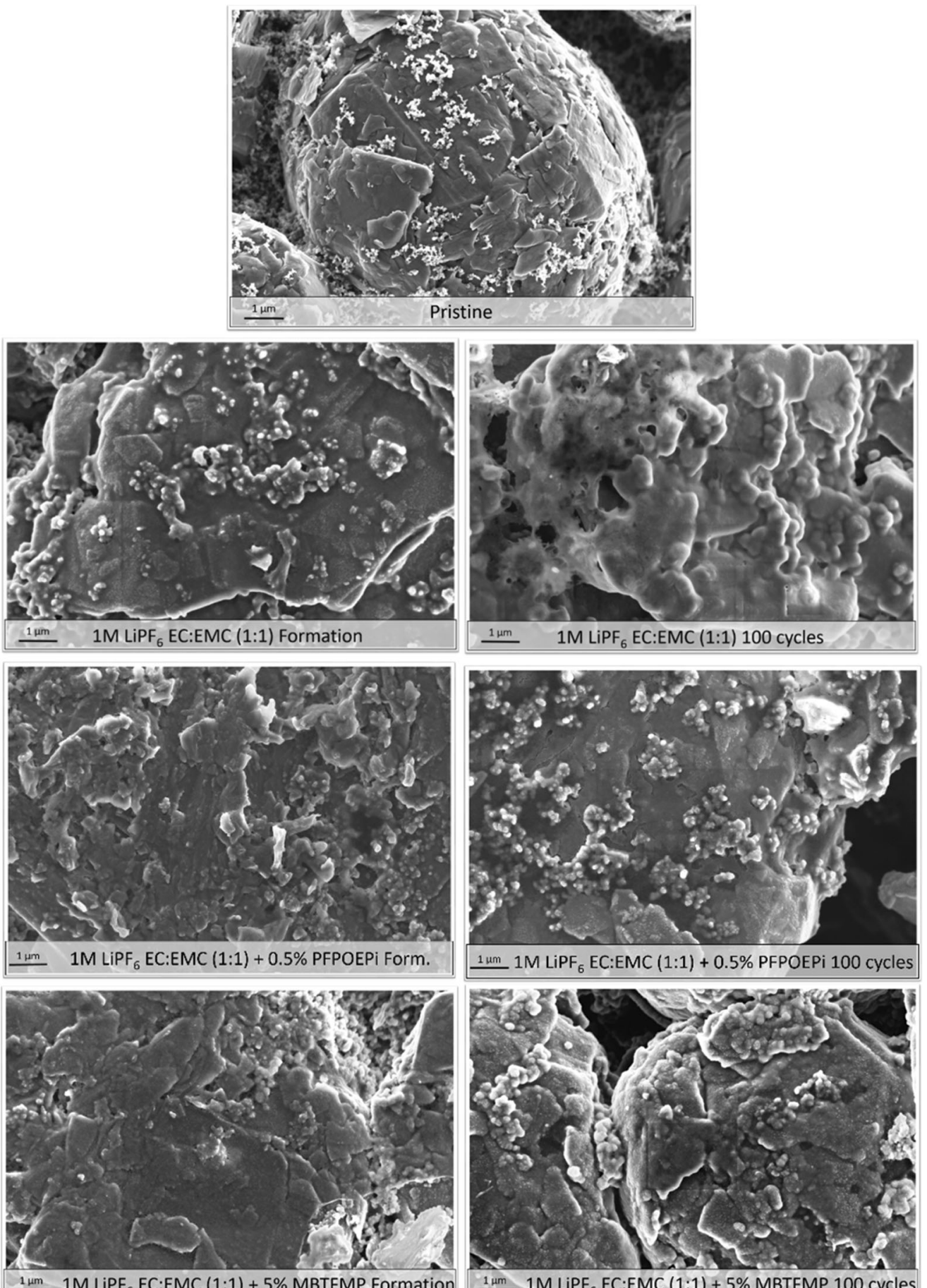

$\underline{1 \mu \mathrm{m}} 1 \mathrm{MLiPF}_{6}$ EC:EMC $(1: 1)+5 \%$ MBTFMP Formation
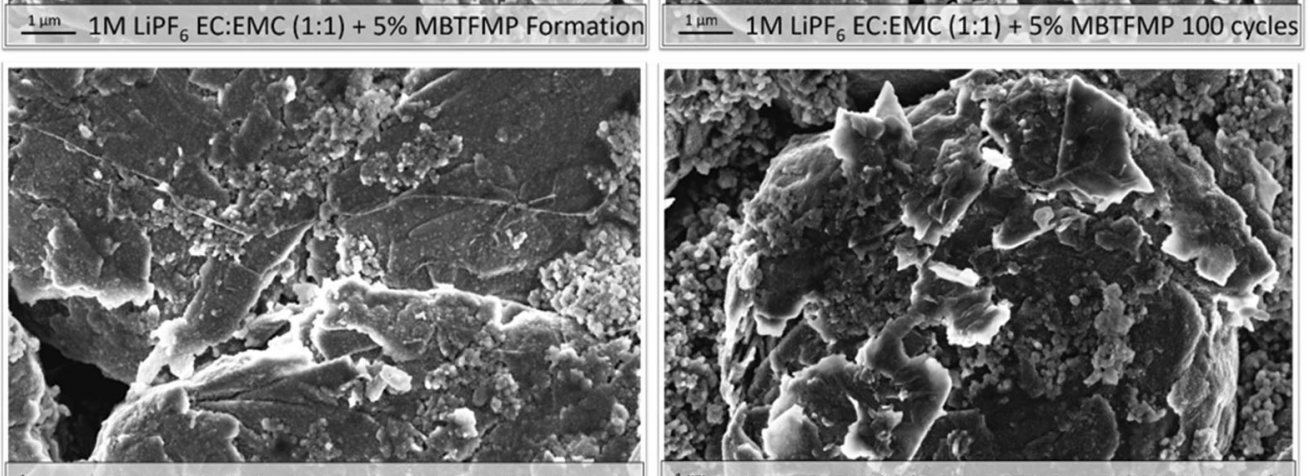

$1 \mu \mathrm{m} 1 \mathrm{M}$ LiPF $_{6}$ EC:EMC $(1: 1)+5.0 \%$ MBTFMP + 0.5\% PFPOEPi Formation

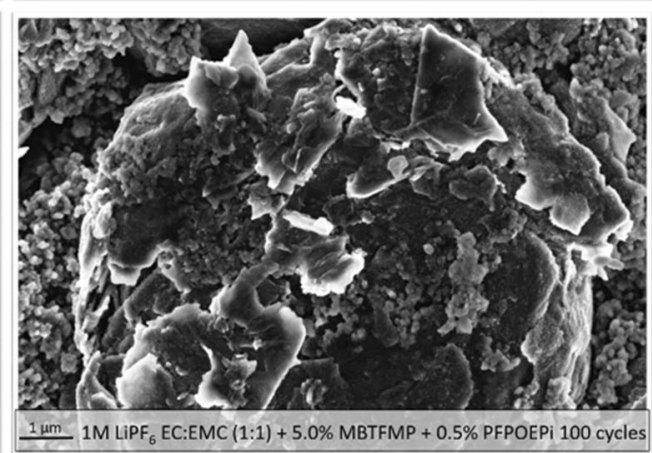


and composition of the formed SEI, XPS analysis was carried out and the obtained results are illustrated in Fig. 7.

The obtained SEI thickness values considering the additive mixture-containing electrolyte formulation reveal an impact of both functional additives on SEI formation and dynamics. The SEI thickness of anodes from the additive mixturecontaining electrolyte formulation is between those of anodes of the single-additive-containing cells after formation. After 100 charge/discharge cycles, the SEI thickness of the all three additive-containing cells is similar after 100 charge/discharge cycles. Moreover, the composition of the additive mixturecontaining electrolyte formulation in respect to the organic and inorganic parts is similar to the MBTFMP-containing cell after 100 charge/discharge cycles. Herein, the increase in the SEI thickness is not as pronounced as for the MBTFMPcontaining cells, which is influenced by the PFPOEPi additive. Furthermore, the presence of PFPOEPi additive impacts the increase of the organic content of the SEI after formation compared with the MBTFMP cells. However, the organic layer is thinner than for the PFPOEPi-containing cells. The influence of additives is indirect as the N $1 \mathrm{~s}$ and $\mathrm{C} 1 \mathrm{~s}$ core spectra (Fig. 7b, c) reveal no decomposition of the PFPOEPi or the MBTFMP additive on the electrode surface. With this in mind, it can be concluded that the impact of the functional
Fig. 7 a Determined thicknesses of the organic and inorganic parts of the SEI, $\mathbf{b} \mathrm{N} 1 \mathrm{~s}$ core spectra, and $\mathbf{c} \mathrm{C} 1 \mathrm{~s}$ core spectra of the considered electrolyte formulations $\left(1 \mathrm{M} \mathrm{LiPF}_{6}\right.$ EC:EMC (1:1 by wt.) (REF), REF + 0.5\% PFPOEPi, REF + $5 \%$ MBTFMP, and REF $+0.5 \%$ PFPOEPi + 5\% MBTFMP) after formation and 100 charge/ discharge cycles
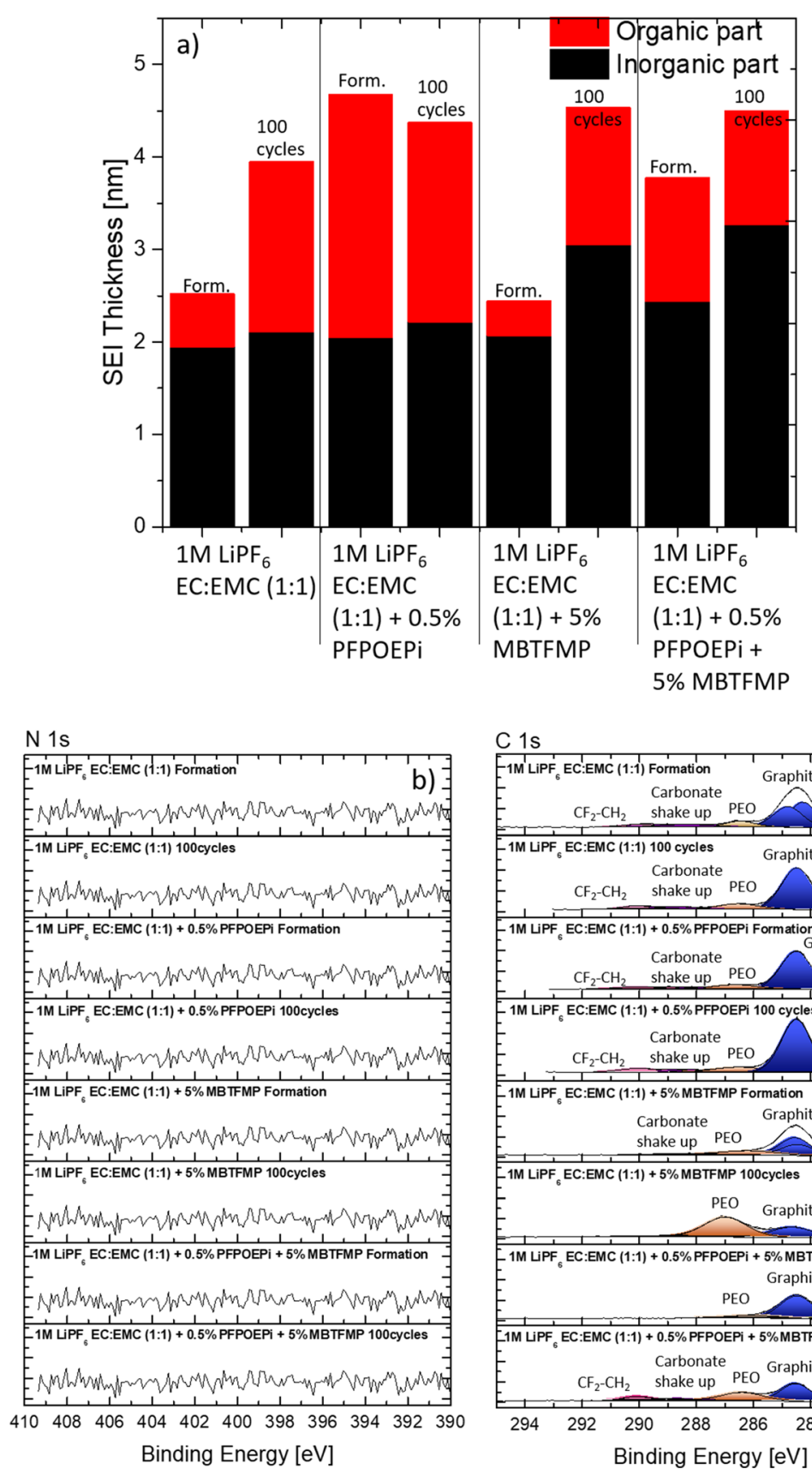
additives on improved cycling performance is determined by their decomposition and formation of the CEI at the cathode surface. Furthermore, when looking into the combination of the additives PFPOEPi and MBTFMP, an influence on both electrodes is observable. The impact of the additive PFPOEPi is low on both interphases, whereas the decomposition of the MBTFMP additive dominates at the cathode surfaces. As the EIS results reveal, the cathode side in the battery cell is mainly responsible for the cycling performance and, therefore, the additive MBTFMP mainly determines the cycling performance of the additive mixture containing electrolyte formulation.

\section{Conclusion}

A functional additive mixture-containing electrolyte formulation consisting of a phospholane- and a pyrazole-based additive was systematically investigated for high voltage application in LIBs and correlated to the single-additive-containing electrolyte formulations to determine the influence of each additive in the additive mixture-containing electrolyte and to evaluate whether the single-additive or the additive mixture approach is more effective for the development of advanced LIBs. The obtained results revealed similar cycling performance of the additive mixture-containing electrolyte formulation to the MBTFMP-containing cells. The reason behind this observation is related to formation of the respective interphases at anode and cathode. In the case of SEI formation, the synergistic effect of the two functional additives was well observed after the formation step and after 100 charge/ discharge cycles. However, the considered additives do not directly decompose at the graphite surface, and SEI formation is only indirectly influenced. EIS analysis points out that the MBTFMP additive impacts the formation of an effective interphase (also observable in the XPS results), whereas the PFPOEPi additive is responsible for a decreased $R_{c t}$ in the additive mixture-containing cells. However, as the cycling performance of the additive mixture-containing cells is similar to the MBTFMP-containing cells, the resistance originating from the CEI is apparently more relevant for the cycling performance than the reduced $\mathrm{R}_{\mathrm{ct}}$. Moreover, the obtained XPS data reveal that both functional additives in the additive mixture-containing electrolyte formulation decompose at the NMC111 surface. The MBTFMP additive mainly determines the thickness of the CEI, but still the PFPOEPi additive influences the CEI composition. By correlating these findings with the galvanostatic cycling results, it can be concluded that changes in CEI composition induced by the PFPOEPi additive have no impact on the overall cycling performance.

In addition, this work shows that the polymerization reaction of the phospholane molecule via ring opening is more effective for the formation of an effective CEI as the complex formation of the pyrazole-based molecule with the transition metals present in the NMC111 surface. This systematical approach reveals that the selection of the right additive mixture, the optimum amount of each functional additive, and the understanding of their effectiveness and performance are essential for the development of advanced electrolyte formulations for lithium-based batteries. This work is also a most illustrative example for the power of electrochemical and analytical techniques $[9,10]$ to identify the "best" material or material combination for a specific electrochemical application.

Acknowledgements This work was supported by the state of NRW (Ministerium für Kultur und Wissenschaft des Landes Nordrhein Westfalen, grant number 433).

Funding Open Access funding enabled and organized by Projekt DEAL.

Open Access This article is licensed under a Creative Commons Attribution 4.0 International License, which permits use, sharing, adaptation, distribution and reproduction in any medium or format, as long as you give appropriate credit to the original author(s) and the source, provide a link to the Creative Commons licence, and indicate if changes were made. The images or other third party material in this article are included in the article's Creative Commons licence, unless indicated otherwise in a credit line to the material. If material is not included in the article's Creative Commons licence and your intended use is not permitted by statutory regulation or exceeds the permitted use, you will need to obtain permission directly from the copyright holder. To view a copy of this licence, visit http://creativecommons.org/licenses/by/4.0/.

\section{References}

1. Wagner R, Preschitschek N, Passerini S, Leker J, Winter M (2013) J Appl Electrochem 43(5):481-496

2. Betz J, Bieker G, Meister P, Placke T, Winter M, Schmuch R (2019) Adv Energy Mater 9(6):1803170

3. Winter M, Barnett B, Xu K (2018) Chem Rev 118(23):1143311456

4. Placke T, Kloepsch R, Dühnen S, Winter M (2017) J Solid State Electrochem 21(7):1939-1964

5. Schmuch R, Wagner R, Hörpel G, Placke T, Winter M (2018) Nat Energy 3(4):267-278

6. Cekic Laskovic I, von Aspern N, Imholt L, Kaymaksiz S, Oldiges K, Rad BR, Winter M (2017) Top Curr Chem 375:37-101

7. von Aspern N, Röschenthaler G-V, Winter M, Cekic-Laskovic I (2019) Angew Chem Int Ed 58:2-25

8. Scholz F, Doménech-Carbó A (2019) Angew Chem Int Ed 58(11): 3279-3284

9. Scholz F (ed) (2010) Electroanalytical methods: guide to experiments and applications. Springer-Verlag, Berlin Heidelberg

10. Grygar T, Marken F, Schröder U, Scholz F (2002) Collect Czechoslov Chem Commun 67(2):163-208

11. Winter M, Imhof R, Joho F, Novák P (1999) J Power Sources 8182:818-823

12. Krämer E, Passerini S, Winter M (2012) ECS Electrochem Lett 1(5):C9-C11

13. Korepp C, Santner HJ, Fujii T, Ue M, Besenhard JO, Möller KC, Winter M (2006) J Power Sources 158:578-582

14. Zhang SS (2006) J Power Sources 162(2):1379-1394 
15. Aupperle F, von Aspern N, Berghus D, Weber F, Eshetu GG, Winter M, Figgemeier E (2019) ACS Appl Energy Mater 2(9): $6513-6527$

16. Winter M (2009) Z Phys Chem 223(10-11):1395-1406

17. Gallus DR, Wagner R, Wiemers-Meyer S, Winter M, CekicLaskovic I (2015) Electrochim Acta 184:410-416

18. Qian Y, Niehoff P, Börner M, Grützke M, Mönnighoff X, Behrends P, Nowak S, Winter M, Schappacher FM (2016) J Power Sources 329:31-40

19. Winter M, Besenhard JO (1999) In: Besenhard JO (ed) Handbook of battery materials, vol 3. Weinheim, $\mathrm{VCH}$

20. Hu M, Pang X, Zhou Z (2013) J Power Sources 237:229-242

21. Wagner R, Streipert B, Kraft V, Reyes Jimenez A, Roeser S, Kasnatscheew J, Gallus D, Boerner M, Mayer C, Arlinghaus HF, Korth M, Amereller M, Cekic-Laskovic I, Winter M (2016) Adv Mater Interfaces 2016(3):1600096

22. von Aspern N, Diddens D, Kobayashi T, Börner M, StubbmannKazakova O, Kozel V, Röschenthaler G-V, Smiatek J, Winter M,
Cekic-Laskovic I (2019) ACS Appl Mater Interfaces 11(18): 16605-16618

23. von Aspern N, Grünebaum M, Diddens D, Pollard TP, Wölke C, Borodin O, Winter M, Cekic-Laskovic I (2020) J Power Sources 461:228159-228169

24. Nölle R, Beltrop K, Holtstiege F, Kasnatscheew J, Placke T, Winter M (2019) Mater Today 32:131-146

25. Petibon R, Aiken CP, Sinha NN, Burns JC, Ye H, VanElzen CM, Jain G, Trussler S, Dahn JR (2013) J Electrochem Soc 160:A117A124

26. Niehoff P, Winter M (2013) Langmuir 29(51):15813-15821

27. Niehoff P, Passerini S, Winter M (2013) Langmuir 29(19):58065816

28. Zhao X, Zhuang Q-C, Xu S-D, Xu Y-X, Shi Y-L, Zhang X-X (2015) Int J Electrochem Sci 10:2515-2534

Publisher's note Springer Nature remains neutral with regard to jurisdictional claims in published maps and institutional affiliations. 